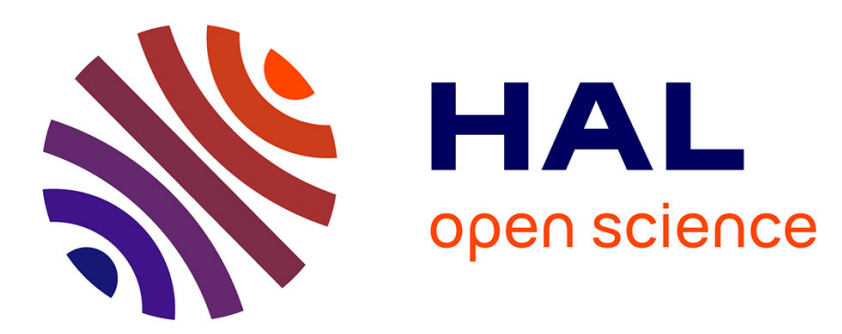

\title{
Field application of passive SBSE for the monitoring of pesticides in surface waters
}

A. Assoumani, Marina Coquery, L. Liger, Nicolas Mazzella, C. Margoum

\section{To cite this version:}

A. Assoumani, Marina Coquery, L. Liger, Nicolas Mazzella, C. Margoum. Field application of passive SBSE for the monitoring of pesticides in surface waters. Environmental Science and Pollution Research, 2015, 22 (6), pp.3997-4008. 10.1007/s11356-014-3590-4 . hal-01355908

\section{HAL Id: hal-01355908 \\ https://hal.science/hal-01355908}

Submitted on 24 Aug 2016

HAL is a multi-disciplinary open access archive for the deposit and dissemination of scientific research documents, whether they are published or not. The documents may come from teaching and research institutions in France or abroad, or from public or private research centers.
L'archive ouverte pluridisciplinaire HAL, est destinée au dépôt et à la diffusion de documents scientifiques de niveau recherche, publiés ou non, émanant des établissements d'enseignement et de recherche français ou étrangers, des laboratoires publics ou privés. 


\section{Field application of passive SBSE for the monitoring of pesticides in surface 2 waters}

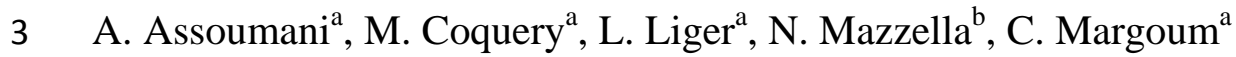

\section{Abstract}

Spot sampling lacks representativeness for monitoring organic contaminants in most surface waters. Passive sampling has emerged as a cost-effective complementary sampling technique. We recently developed passive stir bar sorptive extraction (passive SBSE), with Twister from Gerstel, for monitoring moderately hydrophilic to hydrophobic pesticides $\left(2.18<\log K_{\text {ow }}<\right.$ 5.11) in surface water. The aim of the present study was to assess this new passive sampler for the determination of representative average concentrations and to evaluate the contamination levels of two French rivers. Passive SBSE was evaluated for the monitoring of 16 pesticides in two rivers located in a small vineyard watershed during two one-month field campaigns in spring 2010 and spring 2011. Passive SBSE was applied for periods of one or two weeks during the field campaigns, and compared with spot sampling and weekly average automated sampling. Results showed that passive SBSE could achieve better time-representativeness than spot sampling, and lower limits of quantification than automated sampling coupled to analytical SBSE for the pesticides studied. Finally, passive SBSE proved useful for revealing spatial and temporal variations in pesticide contamination of both rivers, and the impact of rainfall and runoff on the river water quality.

Keywords: Freshwater monitoring, Passive sampling, Spot sampling, Pesticides 


\section{Introduction}

Monitoring organic contaminants in the aquatic environment is a critical issue, as many of them can cause adverse effects. Currently, spot sampling is the most commonly used method for monitoring water quality (Greenwood et al. 2007b; Madrid and Zayas 2007); 4-12 spot samples per year are required to implement monitoring programs for the Water Framework Directive (European Commission, 2000). For most hydrosystems, frequent spot sampling is necessary for good time-representativeness. However, the cost can be high because of the labor and transport involved in sampling, and the need for a large number of analyses (Roig et al. 2007). Automated sampling achieves better time-representativeness than spot sampling, with lower logistical cost, and also with lower analytical cost when composite samples are collected and analyzed. However, this technique is costly for purchase and maintenance, cannot be used at all sites, and can only be used to monitor stable molecules (Morin et al. 2012). Alternative sampling methods, such as passive sampling, are being developed, and may provide more representative data than spot sampling. However, the reliability, reproducibility and sensitivity of these methods first need to be assessed in both laboratory and field studies before they can be applied (Greenwood et al. 2007b).

Passive sampling is a recently developed sampling method for monitoring contaminants in surface waters (Namieśnik et al. 2005; Vrana et al. 2005; Greenwood et al. 2007a). This technique allows smoothed integrative sampling over periods ranging from days to months, and ultra-trace levels of detection for a broad range of organic contaminants (Huckins et al. 2006; Greenwood et al. 2007a). For determining time-weighted average (TWA) concentrations, the passive sampler has to be calibrated prior to field exposure. In fact, the accumulation kinetics of the target organic contaminants are studied in controlled conditions to determine the corresponding sampling rates $\left(R_{\mathrm{S}}\right)$. The efficiency of passive samplers for the 
determination of TWA concentrations in natural waters is generally assessed by comparison with active sampling (Vrana et al. 2005; Greenwood et al. 2007a). In most cases, passive sampling has been compared with spot sampling with globally positive results. For instance, Alvarez et al. (2004) obtained an agreement in the concentrations of diuron and isoproturon in two rivers with a less than 1.7 -fold difference between the POCIS and spot sampling. Kaserzon et al. (2012) also observed a close agreement between perfluorinated chemicals measured by repeated spot sampling and POCIS in Sidney Harbor water. However, fewer studies report comparisons with automated sampling, although this provides better timerepresentativeness (Hyne and Aistrope 2008; Mazzella et al. 2010; Morin et al. 2012; Bailly et al. 2013).

Floods are a major pathway for the transport of pesticides into dynamic rivers located in small agricultural watersheds (Kreuger 1998; Taghavi et al. 2011; Petersen et al. 2012), when spot sampling usually under-estimates the contamination levels (Rabiet et al. 2010; Dalton et al. 2014). Recently, we used Gerstel Twisters ${ }^{\circledR}$ (commercially available devices used for stir bar sorptive extraction (SBSE)) to develop passive SBSE as a simple passive sampling technique for moderately hydrophilic to hydrophobic pesticides $\left(2.18<\log K_{\mathrm{ow}}<5.11\right)$ (Assoumani et al. 2013). Stir bar sorptive extraction is originally an analytical sample preparation technique for liquid and gaseous samples (Baltussen et al. 1999). Vrana et al. (2001) also used Twisters ${ }^{\circledR}$ and developed the membrane-enclosed sorptive coating (MESCO) for the passive sampling of polycyclic aromatic hydrocarbons (PAH) and polychlorobiphenyls (PCB) in water. Equipped with a membrane, the accumulation kinetics of organic contaminants in the MESCO might not be fast enough to integrate transient variations of concentrations. In contrast, for membrane-free passive SBSE, we reported fast accumulation kinetics for the 18 target pesticides in laboratory conditions (Assoumani et al. 2014). This new passive sampler needed to be assessed in field conditions and compared with conventional active sampling 
techniques. Hence, the aim of the present work was, first, to evaluate passive SBSE for the determination of representative pesticide concentrations and, second, to assess the contamination levels of two French rivers. We conducted two one-month monitoring campaigns, in spring 2010 and spring 2011, to assess the time-representativeness and sensitivity of passive SBSE for the monitoring of 16 pesticides in river waters. Firstly, we compared the results of passive SBSE with those of spot sampling and weekly average automated sampling. We focused on qualitative and quantitative results, and on the limits of quantification allowed by the three sampling techniques. Secondly, passive SBSE results were used to assess the pesticide contamination of two river waters. Spatial and temporal variations in the pesticide concentrations were assessed in the two rivers in relation to agrochemical and hydrological conditions.

\section{Experimental}

\subsection{Chemicals and materials}

The 16 pesticides selected for this study were acetochlor (ATC), atrazine (ATZ), azoxystrobin (AZS), chlorfenvinphos (CFV), chlorpyrifos-ethyl (CPE), diflufenican (DFF), dimethomorph (DMM), 3,4-dichloroaniline (DCA) (metabolite of diuron), fenitrothion (FNT), flufenoxuron (FFX), isoproturon (IPU), metolachlor (MTC), norflurazon (NFZ), procymidon (PCM), simazine (SMZ), and tebuconazole (TBZ) (purity $\geq 92.5 \%$ ) (Dr. Ehrenstorfer $\mathrm{GmbH}$, Augsburg, Germany). They belong to different use classes (herbicides, insecticides and fungicides) and chemical classes (triazines, substituted ureas, triazoles and organophosphate compounds); their physical and chemical properties, including their octanol-water partitioning coefficient $\left(\log K_{\text {ow }}\right)$, range widely (Table 1$)$. 
For chemical analyses, diuron-d6 (used as internal standard), linuron-d6 and chlorpyrifosethyl-d10 (used as surrogates), were provided by Dr. Ehrenstorfer (purity $\geq 98.5 \%$ ). Sodium chloride $\mathrm{NaCl}$ (purity $=99.5 \%$ ) was purchased from VWR (Strasbourg, France). Dichloromethane for pesticide residue analysis, and liquid chromatography-mass spectrometry (LC-MS) grade acetonitrile and methanol were purchased from VWR (Strasbourg, France). Formic acid (purity $=98 \%$ ) for LC-MS analysis was provided by Sigma-Aldrich (Saint-Quentin-Fallavier, France). Ultrapure water was produced by a MilliQ water purification system equipped with an LC-Pak cartridge purchased from Millipore (Billerica, MA, USA). For passive SBSE, we used Twisters® $(20 \mathrm{~mm} \times 1 \mathrm{~mm}$ thick polydimethylsiloxane (PDMS) film) as passive sampling tools, hereafter named passive Twisters, purchased from Gerstel (Mülheim a/d Ruhr, Germany). For the field application, the passive Twisters were placed in deployment bags, made of two pieces of plastic mesh, in order to expose the PDMS phase directly to the aquatic medium, and protect it from small rocks, pieces of wood or coarse sand (Assoumani et al. 2013). The deployment bags with passive Twisters were placed in cases with holes $(40 \mathrm{~cm} \times 30 \mathrm{~cm} \times 20 \mathrm{~cm})$, which were placed in the river.

\subsection{Field experiments}

Two monitoring campaigns took place along two rivers of a French vineyard watershed $\left(220 \mathrm{~km}^{2}\right)$ located about $70 \mathrm{~km}$ north of Lyon in the Beaujolais region, the Morcille River and the Ardières River (Figure 1). The Morcille River is a tributary of the Ardières River and is located in a subwatershed of $8 \mathrm{~km}^{2}$. In spring, the typical flow of the Morcille River is $5 \mathrm{~L} \mathrm{~s}^{-1}$ (Figure S1 in Supplementary data section), and the typical flow of the Ardières River is $350 \mathrm{~L}$ $\mathrm{s}^{-1}$ (Figure S2). Typical flood events last $5 \mathrm{~h}$ for the Morcille River and $24 \mathrm{~h}$ for the Ardières 
128 River. The proportion of land devoted to vineyards increases along both rivers. This

proportion increases up to $40 \%$ and to $70 \%$ for the Ardières and the Morcille watersheds, respectively (Rabiet et al. 2010). Six deployment sites, three per river, were selected for two one-month exposure campaigns, in spring 2010 and spring 2011.

For the performance evaluation of passive SBSE, the sampling strategy varied depending on the campaign year and the deployment site (Figure 1). In spring 2010, triplicate passive Twisters were deployed for two periods of two weeks at all the sites. Further triplicate passive Twisters were deployed for four periods of one week at the intermediate site of the Morcille River. Simultaneously, to assess the time-representativeness of passive SBSE, spot sampling and weekly average automated sampling were carried out every week. Spot samples were collected in 1-L amber polyethylene bottles rinsed twice with the river water. The weekly average samples were collected with a refrigerated automated sampler (Bühler 4010, HachLange) in a single $5 \mathrm{~L}$ amber glass container (i.e. composite sample) every week at the intermediate site of the Morcille River and at the downstream site of the Ardières River. The automated samplers were set to collect $100 \mathrm{~mL}$ of river water every $3.5 \mathrm{~h}$. The time interval was short enough to allow the integration of typical floods of the two rivers, and the water volume collected at each time point was selected to allow the operation of the automated samplers for 7 days (48 samples collected) while ensuring satisfactory repeatability.

In spring 2011, triplicate passive Twisters were deployed for four periods of one week at the intermediate site and the downstream site of the Morcille River, and at the upstream site and downstream site of the Ardières River. During the same period, spot samples and weekly average samples (via automated samplers) were collected every week at the intermediate site of the Morcille River and at the downstream site of the Ardières River (Figure 1). 
Field blanks for passive Twisters were systematically used. All the passive Twisters were placed individually in deployment bags, made of two pieces of plastic mesh, in order to expose the PDMS phase directly to the aquatic medium, while protecting it from small rocks, pieces of wood or coarse sand. The water samples and the passive Twisters were brought back to the laboratory in a refrigerated case for subsequent pesticide assays. Hourly rainfall and flow rate were measured at the intermediate site of the Morcille River in spring 2010, and at the intermediate site of the Morcille River and at the downstream site of the Ardières River in spring 2011.

2.3 Chemical analysis of water samples and passive Twisters

Before extraction and determination of pesticide concentrations, all the water samples were filtered with $0.7 \mu \mathrm{m} \mathrm{GF/F}$ glass fiber membranes. In spring 2010, pesticide concentrations in spot samples were determined by solid phase extraction (6 mL Oasis HLB cartridges, Waters) followed by liquid chromatography coupled with tandem mass spectrometry (SPE-LCMS/MS). The extraction was carried out with $250 \mathrm{~mL}$ of water sample, and the concentration factor was 1000 . For the weekly average samples, pesticides were assayed in triplicate by analytical SBSE followed by liquid desorption and liquid chromatography coupled with tandem mass spectrometry (SBSE-LD-LC-MS/MS). In spring 2011, this analytical method was applied for pesticide assay in the spot samples and in the weekly average samples, both in triplicate. The development and validation of the SBSE-LD-LC-MS/MS analytical method have been described elsewhere (Margoum et al., 2013). Briefly, the extraction of $20 \mathrm{~mL}$ of water samples was performed at $800 \mathrm{rpm}$ for $3 \mathrm{~h}$. The Twisters (hereafter named analytical Twisters) were then placed in $200 \mu \mathrm{L}$ of methanol/acetonitrile $(50 / 50, \mathrm{v} / \mathrm{v})$, and the pesticides were desorbed under sonication for $15 \mathrm{~min}$. Finally, $150 \mu \mathrm{L}$ of ultrapure water and $10 \mu \mathrm{L}$ of 
Author-produced version of the article published in Environmental Science and Pollution Research (2015), vol. 22, $n^{\circ} 6, p p .3997-4008$

The original publication is available at http://link.springer.com/article/10.1007\%2Fs11356-014-3590-4 doi:10.1007/s11356-014-3590-4

176 diuron-d6 at $200 \mu \mathrm{g} \mathrm{L}{ }^{-1}$ in acetone, were added to $40 \mu \mathrm{L}$ of the desorbate to constitute the

177 sample for LC-MS/MS analysis. The concentration factor was 20.

178 After exposure, the passive Twisters were taken out of their deployment bags, gently rinsed

179 with ultrapure water and dried with lint-free tissue, and then left at least overnight at $-18{ }^{\circ} \mathrm{C}$.

180 The pesticides sorbed in the passive Twisters were then extracted in the same way as for the

181 analytical Twisters.

182

183

The chemical analyses were performed with an LC 1100 Series apparatus from Agilent (Massy, France) coupled with an MS triple quadrupole API 4000 from AB Sciex (Les Ulis, France), equipped with an electrospray ionization source (ESI) operated in the positive ionization mode. An Atlantis T3 $\left(2.1 \mathrm{~mm} \times 100 \mathrm{~mm} ; d_{\mathrm{p}}=3 \mu \mathrm{m}\right)$ purchased from Waters (Saint-Quentin-en-Yvelines, France) was used for the chromatographic separation of the analytes. Acetonitrile and ultrapure water both with formic acid $(0.1 \%)$ were used in an analytical gradient of $15 \mathrm{~min}$.

\section{Theory}

The theory of passive sampling is well established and documented (Vrana et al. 2005; Huckins et al. 2006; Greenwood et al. 2007a). For passive SBSE, assuming isotropic exchange, the uptake of a contaminant in a passive Twister over time with constant ambient water concentration obeys first-order kinetics (Assoumani et al. 2014). In the initial phase, the chemical uptake is linear and integrative, and defined as follows (Eq. 1):

$$
M_{\mathrm{s}}(t)=C_{\mathrm{w}} R_{\mathrm{s}} t
$$


where $M_{\mathrm{s}}(\mathrm{ng})$ is the mass of contaminant accumulated in the receiving phase, $C_{\mathrm{w}}\left(\mathrm{ng} \mathrm{mL}^{-1}\right)$ the concentration of contaminant in the water phase, $R_{\mathrm{S}}$ the sampling rate $\left(\mathrm{mL} \mathrm{d}^{-1}\right)$, and $t(\mathrm{~d})$ the exposure time.

When a passive Twister is deployed in the field and then retrieved within the linear accumulation period, integrative TWA concentrations can be calculated by Eq. 2:

$$
C_{\mathrm{w}}=\frac{M_{\mathrm{s}}}{R_{\mathrm{s}} t}=\frac{M_{\mathrm{s}}}{V_{\mathrm{e}}}
$$

The product $R_{\mathrm{s}} t$ provides a link between batch extraction, such as SPE or analytical SBSE, and passive sampling, as it equals the extracted water volume $V_{\mathrm{e}}$ (Huckins et al. 2006; Lohmann et al. 2012). The limit of quantification (LQ) of the contaminant in the water for the passive SBSE (in ng. $\mathrm{L}^{-1}$ ) can be calculated by dividing the corresponding LQ in the passive Twister (in ng) by $V_{\mathrm{e}}$, and then compared with the LQ achieved by the batch extraction.

Eq. 1 is a special case of the general uptake (Eq. 3):

$$
M_{\mathrm{s}}(t)=C_{\mathrm{w}} K_{\mathrm{sw}} V_{\mathrm{s}}\left(1-\exp \left(-\frac{R_{\mathrm{s}} t}{K_{\mathrm{sw}} V_{\mathrm{s}}}\right)\right)
$$

where $V_{\mathrm{s}}(\mathrm{L})$ is the volume of the receiving phase, $K_{\mathrm{sw}}$ (adimensional), described as the ratio of the concentration at equilibrium of contaminant in the passive Twister $C_{\mathrm{s}}\left(\mathrm{ng} \mathrm{mL}{ }^{-1}\right)$ to the concentration at equilibrium of contaminant in the water phase $C_{\mathrm{w}}\left(\mathrm{ng} \mathrm{mL}^{-1}\right)$. When the passive Twister is deployed in the field for longer than the linear accumulation period, TWA concentrations can be calculated with Eq. 4, but they are considered non-integrative.

$$
C_{\mathrm{w}}=\frac{M_{\mathrm{s}}}{K_{\mathrm{sw}} V_{\mathrm{s}}\left(1-\exp \left(-\frac{R_{\mathrm{s}} t}{K_{\mathrm{sw}} V_{\mathrm{s}}}\right)\right)}=\frac{M_{\mathrm{s}}}{V_{\mathrm{e}}} .
$$


With Eq. 4, $V_{\mathrm{e}}$, and therefore the LQ in water for the passive SBSE, can be estimated at any time of the deployment (Lohmann et al. 2012).

\section{Results and discussion}

4.1 Comparison of passive SBSE with spot sampling and weekly average automated sampling

Table 1 presents the LQ achieved by the SPE-LC-MS/MS analysis of the spot samples, the

SBSE-LD-LC-MS/MS analysis of the samples collected by the automated sampler, and the

LD-LC-MS/MS analysis of the passive Twisters. The LQ values for water concentrations determined with a signal-to-noise ratio of 10 in a previous study (Assoumani et al. 2014), and for a 7-day deployment of the passive Twisters. We first observed that passive SBSE allowed achieving lower LQ than analytical SBSE for all the target pesticides (factor 1.2 to 167), except for atrazine (11 $\left.\mathrm{ng} \mathrm{L}^{-1}\right)$ and 3,4-dichloroaniline (165 $\mathrm{ng} \mathrm{\textrm {L } ^ { - 1 }}$ ). Passive SBSE LQ values for fenitrothion, chlorfenvinphos and diflufenican, which were among the most hydrophobic target pesticides, were 45 to 167 times lower than analytical SBSE; large $R_{\mathrm{s}}$, thus $V_{\mathrm{e}} 3$ to 6 times greater than the batch extraction volume $(20 \mathrm{~mL})$ were obtained for these compounds during the laboratory calibration (Assoumani et al. 2014). Nonetheless, SPE gave a value of LQ 1.6 to 34 times lower than passive SBSE for the most hydrophilic pesticides (norflurazon, azoxystrobine, dimethomorph, 3,4-dichloroaniline, isoproturon, procymidon, tebuconazole) and flufenoxuron, but required sample volumes 12 times larger. 
Figure 2 and Figure 3 show the concentrations of the pesticides quantified at the intermediate site of the Morcille River in spring 2010 and at the downstream site of the Ardières River in spring 2011, respectively. The pesticide concentrations were obtained from passive SBSE, spot sampling and weekly average automated sampling. For passive SBSE, TWA concentrations were calculated with Eq. 4, and the mass of the pesticides accumulated in the passive Twisters retrieved after 7 or 14 days in the river waters. In Figure 2, out of the 10 pesticides quantified via at least one sampling technique, four were quantified through spot sampling, 10 through passive SBSE, and six through automated sampling. In spring 2010, 3,4-dichloroaniline, isoproturon, fenitrothion and chlorfenvinphos were never quantified by any sampling technique. Over the whole spring 2010 campaign, for the eight pesticides quantified at least once via the three sampling techniques, spot sampling gave a quantification frequency of $35 \%$, whereas passive SBSE and automated sampling gave 52\% and 53\%, respectively.

Likewise, out of the eight pesticides quantified via at least one sampling technique, two were quantified through spot sampling, eight through passive SBSE, and two through automated sampling (Figure 3). In spring 2011, isoproturon, fenitrothion and flufenoxuron were never quantified by any sampling technique. Over the whole spring 2011 campaign, for the 13 pesticides quantified at least once via the three sampling techniques, spot sampling gave a quantification frequency of 5\%, whereas passive SBSE and automated sampling gave 36\% and $17 \%$, respectively. Hence for both campaigns, passive SBSE and automated sampling achieved better time-representativeness of the target pesticide concentrations than spot sampling. 


\subsubsection{Concentrations of the target pesticides}

264

Concentrations of pesticides quantified from spot sampling were generally lower than those obtained from passive SBSE and automated sampling. For instance, in spring 2010, concentrations of norflurazon in the spot samples were five times lower than those calculated from passive SBSE data (Figure 2). The same trend was observed for azoxystrobine and procymidon in spring 2010, and for simazine and azoxystrobine in spring 2011 (Figure 3). Also, several pesticides that were not quantified in the spot samples were quantified by passive SBSE and automated sampling. Diflufenican and chlorpyrifos-ethyl in spring 2010, and dimethomorph, tebuconazole, chlorfenvinphos, acetochlor and diflufenican in spring spring 2011 were not quantified in the spot samples, but were quantified through passive SBSE. The same trend was observed for most results obtained in both campaigns, as shown in Table 2 and Table 3, which present all the concentrations of the target pesticides in the Morcille River and Ardières River during spring 2010 and spring 2011, respectively. Spot samples did not integrate variations of concentrations that probably occurred during the campaigns. These results confirm the observations of Dalton et al. (2014). In that study, low frequency spot sampling systematically gave lower atrazine concentrations than the POCIS deployed for 56 days in rivers located in an agricultural watershed. However, in rare cases, concentrations obtained from spot samples were higher than those determined with passive SBSE, or the number of quantified pesticides was higher for spot samples. This could be due to lower LQ for SPE-LC-MS/MS analysis of the spot samples (e.g. norflurazon and dimethomorph concentrations at the upstream site of the Morcille River in spring 2010), or to high pesticide concentrations in the river water at the precise time of the spot sampling (i.e. 
dimethomorph at the downstream site of the Ardières River on Day 22 (June 15) of the spring 2010 campaign).

The concentrations of the target pesticides obtained from the passive SBSE matched those obtained from automated sampling (e.g. dimethomorph, procymidon and tebuconazole in spring 2010, Figure 2). No performance reference compound (PRC) (Booij et al. 1998; Huckins et al. 2002; Smedes 2007) was used for the calculations of the TWA concentrations obtained from passive SBSE. During both field campaigns, TWA concentrations of the pesticides with $\log K_{\mathrm{ow}}$ values below 3.3 were similar to those determined via automated sampling (i.e. from simazine to metolachlor, Table 1) (Figure 2 and Figure 3). Therefore, for those pesticides, it seems that TWA concentrations calculated without using a PRC were accurate. Recently, we investigated the influence of flow velocity (up to $2.5 \mathrm{~cm} \mathrm{~s}^{-1}$ ) and temperature $\left(10\right.$ and $\left.25^{\circ} \mathrm{C}\right)$ on pesticide uptake in passive Twisters for the same pesticides as in the present study (Assoumani et al. 2014). No significant effect of either parameter was observed for the pesticides with $\log K_{\text {ow }}$ lower than 3.3; we therefore assumed membranecontrolled accumulation kinetics. This means that no PRC would be required for the determination of accurate TWA concentrations of these pesticides. The results obtained in this field study confirm the observations made in that previous laboratory study. Good agreement between concentrations derived from passive sampling and active sampling were also obtained in previous studies. Hyne and Aistrope (2008) observed concentrations of pesticides in 24-hour composite water samples within two fold of the TWA concentrations derived for their cellulose sampling device. Also, although only spot sampling was used as a comparison, Ibrahim et al. (2013) reported good representativeness for TWA concentrations of pesticides derived from POCIS. 
Hence (i) spot sampling lacked temporal representativeness and tended to under-estimate contaminant concentrations in rivers, and (ii) passive SBSE gave a representative insight into pesticide contamination in both rivers, as shown by the close agreement of passive SBSE with automated sampling results.

4.2 Determination of pesticide contamination with passive SBSE

4.2.1 Spatial variations in pesticide concentrations

In spring 2010, concentration gradients were observed from the upstream site to the downstream site of both rivers (Table 2). During the first 14 days of the field campaign, the concentrations of all the quantified pesticides except diflufenican and acetochlor increased along the Ardières River. Neither herbicide is used for wine-growing, and so is not expected at increasing concentrations along a river of a vineyard watershed. The presence of diflufenican in water might be due to residues from earlier use remaining in the soil, given its relatively high $\log K_{\mathrm{ow}}$ (4.20) and high $K_{\mathrm{oc}}$ values $\left(3186 \mathrm{~mL} \mathrm{~g}^{-1}\right.$ ) (Petersen et al. 2012). A dilution effect could then explain the decrease in the diflufenican concentration at the downstream site. Also, there was a maize field near the upstream site, so applications of herbicides might explain the presence of acetochlor in the river. In the Morcille River, the concentrations of all the quantified pesticides, except norflurazon, atrazine, metolachlor and diflufenican, increased from upstream to downstream. These four herbicides were not expected to increase along the Morcille River, since norflurazon was banned in 2004 and atrazine in 2003, and metolachlor and diflufenican are not used for wine-growing. The observed pesticide concentration gradients can be explained by the strong increase in the proportion of land devoted to vineyards along both rivers (Rabiet et al. 2010). 
In spring 2011, similar concentration gradients were observed, although water sampling was carried out at only two sites per river (Table 3). The concentrations of all the quantified pesticides except chlorfenvinphos and diflufenican increased along the Ardières River for all the weeks of the campaign. Likewise, the concentrations of all quantified pesticides except dimethomorph increased along the Morcille River. Therefore, passive SBSE is sensitive enough to highlight concentration gradients of the target pesticides at ultra-trace levels.

\subsubsection{Temporal variations in pesticide concentrations}

Regarding temporal variations in TWA concentrations, decreases of $10-91 \%$ were observed for all the quantified pesticides between the first period (Days 1-15) and the second period (Days 15-29) for the spring 2010 campaign at the upstream site and the downstream site of the Ardières River (Table 2). The data at the intermediate site are missing because of onsite vandalism during the second sampling period. These decreases can be linked to heavy rainfall during the first half of the campaign, and especially on Day 13 (June 6) when precipitations lasted $3 \mathrm{~h}$ with a peak at $46 \mathrm{~mm} \mathrm{~h}^{-1}$ (Figure $\mathrm{S} 1$ ). Hence runoff from the vineyards to the rivers was probably responsible for the high pesticide TWA concentrations measured during this period. The same trend was observed in the Morcille River, presumably for the same reasons. The concentrations of all quantified pesticides except procymidon decreased from the first to the second period of the campaign at the upstream site and the downstream site (decreases of $11-91 \%$, depending on the pesticide). At the intermediate site, all the quantified pesticides except procymidon and tebuconazole were quantified at lower concentrations during the last 14 days of the campaign (decreases of 25-45\%). Spring 2011 was drier than spring 2010 (Figure S2), and pesticide TWA concentrations were generally lower than in spring 2010. However, some rainfall caused increases in the river flows, which may be related to the 
increases in some pesticide concentrations (Kreuger 1998; Louchart et al. 2001; Rabiet et al. 2010; Taghavi et al. 2011; Petersen et al. 2012). At the downstream site of the Ardières River, the increases in the concentrations of simazine, dimethomorph, tebuconazole and diflufenican from the first week to the second week of the campaign could be linked to rainfall that occurred on Day 8 (May 31) (Table 3). Similarly, increases in the concentrations of simazine, atrazine, dimethomorph, metolachlor, tebuconazole and diflufenican from the third week to the fourth week, at the downstream site of the Ardières River, may have been caused by rainfall that occurred on Day 24 (June 16).

A few events of severe spot contaminations were detected via passive SBSE during both campaigns. In spring 2010, the rainfall on Day 13 (June 6) probably triggered a concentration peak of chlorpyrifos-ethyl, quantified at $9011 \mathrm{ng} \mathrm{L}^{-1}$, at the downstream site of the Morcille River during the first week of the field campaign. Interestingly, this could also explain the high chlorpyrifos-ethyl concentration (356 $\mathrm{ng} \mathrm{\textrm {L } ^ { - 1 }}$ ) obtained during the same period at the downstream site of the Ardières River: this site is close (at about $800 \mathrm{~m}$ ) to the downstream site of the Morcille River (Figure 1). Likewise, on Day 23 (June 16), rainfall caused an increase in dimethomorph concentration at the downstream site of the Morcille River (up to $969 \mathrm{ng} \mathrm{L}^{-1}$ ), and also an increase in the concentration of the same pesticide at the downstream site of the Ardières River (up to $668 \mathrm{ng} \mathrm{L}^{-1}$ ). Finally, as observed in spring 2010, an acetochlor contamination at the upstream site of the Ardières River, linked to the maize field upstream from this sampling site, was quantified in spring 2011 for 3 weeks (from 816 to 216 $\left.n g \mathrm{~L}^{-1}\right)$

\section{Conclusion}


The time-representativeness of this new passive sampling technique over periods of one or two weeks was better than spot sampling. Moreover, while presenting results similar to those obtained from automated sampling at lower cost, the passive SBSE gave lower LQ for most hydrophobic compounds, allowing the quantification of lower concentrations of the target pesticides in water. This simple, cost-effective and environmentally friendly sampling technique is therefore well suited to determining average estimates of pesticides in dynamic rivers. The small size of the passive Twisters allows extensive deployment in field studies, with simple handling and preparation before deployment, and in situ use. Lastly, passive SBSE designed for the study of pesticide contamination can tell us not only the spatial and temporal variations in pesticide concentrations, but also the impact of rainfall and runoff on the chemical quality of small rivers located in an agricultural watershed.

\section{Acknowledgments}

The authors thank S. Chataing and C. Guillemain for analytical support, O. Garcia and B. Motte for technical and logistical support, and both the French National Research Agency (ANR) through the PoToMAC project (ANR 2011 CESA 022 02) and the French National Agency for Water and Aquatic Environments (ONEMA) for financial support. The authors also thank ATT for English language editing. 


\section{References}

Alvarez DA, Petty JD, Huckins JN, et al. (2004) Development of a passive, in situ, integrative sampler for hydrophilic organic contaminants in aquatic environments. Environ Toxicol Chem 23:1640-1648. doi: 10.1897/03-603

Assoumani A, Lissalde S, Margoum C, et al. (2013) In situ application of stir bar sorptive extraction as a passive sampling technique for the monitoring of agricultural pesticides in surface waters. Sci Total Environ 463-464:829-835. doi: 10.1016/j.scitotenv.2013.06.025

Assoumani A, Margoum C, Chataing S, et al. (2014) Use of passive stir bar sorptive extraction as a simple integrative sampling technique of pesticides in freshwaters: Determination of sampling rates and lag-phases. J Chromatogr A 1333:1-8. doi: 10.1016/j.chroma.2014.01.063

Bailly E, Levi Y, Karolak S (2013) Calibration and field evaluation of polar organic chemical integrative sampler (POCIS) for monitoring pharmaceuticals in hospital wastewater. Environ Pollut 174:100-105. doi: 10.1016/j.envpol.2012.10.025

Baltussen E, Sandra P, David F, Cramers C (1999) Stir bar sorptive extraction (SBSE), a novel extraction technique for aqueous samples: Theory and principles. $\mathrm{J}$ Microcolumn Sep 11:737-747. doi: 10.1002/(SICI)1520667X(1999)11:10<737::AID-MCS7>3.0.CO;2-4

Booij K, Sleiderink HM, Smedes F (1998) Calibrating the uptake kinetics of semipermeable membrane devices using exposure standards. Environ Toxicol Chem 17:1236-1245. doi: 10.1002/etc.5620170707

Dalton RL, Pick FR, Boutin C, Saleem A (2014) Atrazine contamination at the watershed scale and environmental factors affecting sampling rates of the polar organic chemical integrative sampler (POCIS). Environ Pollut 189:134-142. doi: 10.1016/j.envpol.2014.02.028

Directive 2000/60/EC of the European Parliament and of the Council of 23 October 2000 establishing the framework for Community action in the field of water policy. OJ L 327, 22.12.2000, pp.1-73.

Greenwood R, Mills GA, Vrana B (2007a) Passive sampling techniques in environmental monitoring (Comprehensive analytical chemistry, Vol. 48).

Greenwood R, Mills GA, Roig B (2007b) Introduction to emerging tools and their use in water monitoring. TrAC - Trends Anal Chem 26:263-267. doi: 10.1016/j.trac.2006.12.006

Huckins JN, Petty JD, Booij K (2006) Monitors of Organic Chemicals in the Environment: Semipermeable Membrane Devices. New York, NY 
Huckins JN, Petty JD, Lebo JA, et al. (2002) Development of the Permeability/Performance Reference Compound Approach for In Situ Calibration of Semipermeable Membrane Devices. Environ Sci Technol 36:85-91. doi: 10.1021/es010991w

Hyne RV, Aistrope M (2008) Calibration and field application of a solvent-based cellulose membrane passive sampling device for the monitoring of polar herbicides. Chemosphere 71:611-620. doi: 10.1016/j.chemosphere.2007.11.017

Ibrahim I, Togola A, Gonzalez C (2013) In-situ calibration of POCIS for the sampling of polar pesticides and metabolites in surface water. Talanta 116:495-500. doi: 10.1016/j.talanta.2013.07.028

Kaserzon SL, Kennedy K, Hawker DW, et al. (2012) Development and Calibration of a Passive Sampler for Perfluorinated Alkyl Carboxylates and Sulfonates in Water. Environ Sci Technol 46:4985-4993. doi: 10.1021/es300593a

Kreuger J (1998) Pesticides in stream water within an agricultural catchment in southern Sweden, 1990-1996. Sci Total Environ 216:227-251. doi: 10.1016/S00489697(98)00155-7

Lohmann R, Booij K, Smedes F, Vrana B (2012) Use of passive sampling devices for monitoring and compliance checking of POP concentrations in water. Environ Sci Pollut Res 19:1885-1895. doi: 10.1007/s11356-012-0748-9

Louchart X, Voltz M, Andrieux P, Moussa R (2001) Herbicide Transport to Surface Waters at Field and Watershed Scales in a Mediterranean Vineyard Area. J Environ Qual 30:982. doi: 10.2134/jeq2001.303982x

Madrid Y, Zayas ZP (2007) Water sampling: Traditional methods and new approaches in water sampling strategy. TrAC Trends Anal Chem 26:293-299. doi: 10.1016/j.trac.2007.01.002

Margoum C, Guillemain C, Yang X, Coquery M (2013) Stir bar sorptive extraction coupled to liquid chromatography-tandem mass spectrometry for the determination of pesticides in water samples: Method validation and measurement uncertainty. Talanta 116:1-7. doi: 10.1016/j.talanta.2013.04.066

Mazzella N, Lissalde S, Moreira S, et al. (2010) Evaluation of the Use of Performance Reference Compounds in an Oasis-HLB Adsorbent Based Passive Sampler for Improving Water Concentration Estimates of Polar Herbicides in Freshwater. Environ Sci Technol 44:1713-1719. doi: 10.1021/es902256m

Morin N, Miège C, Coquery M, Randon J (2012) Chemical calibration, performance, validation and applications of the polar organic chemical integrative sampler (POCIS) in aquatic environments. TrAC Trends Anal Chem 36:144-175. doi: 10.1016/j.trac.2012.01.007

Namieśnik J, Zabiegała B, Kot-Wasik A, et al. (2005) Passive sampling and/or extraction techniques in environmental analysis: a review. Anal Bioanal Chem 381:279-301. doi: $10.1007 / \mathrm{s} 00216-004-2830-8$ 
Author-produced version of the article published in Environmental Science and Pollution Research (2015), vol. 22, ${ }^{\circ}$ 6, pp. $3997-4008$

The original publication is available at http://link.springer.com/article/10.1007\%2Fs11356-014-3590-4 doi:10.1007/s11356-014-3590-4

Petersen J, Grant R, Larsen SE, Blicher-Mathiesen G (2012) Sampling of herbicides in streams during flood events. J Environ Monit 14:3284-3294. doi: 10.1039/C2EM30771E

Rabiet M, Margoum C, Gouy V, et al. (2010) Assessing pesticide concentrations and fluxes in the stream of a small vineyard catchment - Effect of sampling frequency. Environ Pollut 158:737-748. doi: 10.1016/j.envpol.2009.10.014

Roig B, Valat C, Allan IJ, et al. (2007) The use of field studies to establish the performance of a range of tools for monitoring water quality. TrAC - Trends Anal Chem 26:274-282. doi: $10.1016 /$ j.trac.2007.02.005

Smedes F (2007) Monitoring of chlorinated biphenyls and polycyclic aromatic hydrocarbons by passive sampling in concert with deployed mussels. Passive Sampl. Tech. Environ. Monit. Greenwood, R., Mills, G., Vrana, B., pp 407-447

Taghavi L, Merlina G, Probst J-L (2011) The role of storm flows in concentration of pesticides associated with particulate and dissolved fractions as a threat to aquatic ecosystems - Case study: the agricultural watershed of Save river (Southwest of France). Knowl Manag Aquat Ecosyst 06. doi: 10.1051/kmae/2011002

Vrana B, Mills G, Allan I, et al. (2005) Passive sampling techniques for monitoring pollutants in water. TRAC-TRENDS Anal Chem 24:845-868. doi: 10.1016/j.trac.2005.06.006

Vrana B, Popp P, Paschke A, Schüürmann G (2001) Membrane-Enclosed Sorptive Coating. An Integrative Passive Sampler for Monitoring Organic Contaminants in Water. Anal Chem 73:5191-5200. doi: 10.1021/ac010630z 
Author-produced version of the article published in Environmental Science and Pollution Research (2015), vol. 22, $n^{\circ} 6, p p .3997-4008$

The original publication is available at http://link.springer.com/article/10.1007\%2Fs11356-014-3590-4 doi:10.1007/s11356-014-3590-4

501

2010

\section{Saône River}

Ardières River

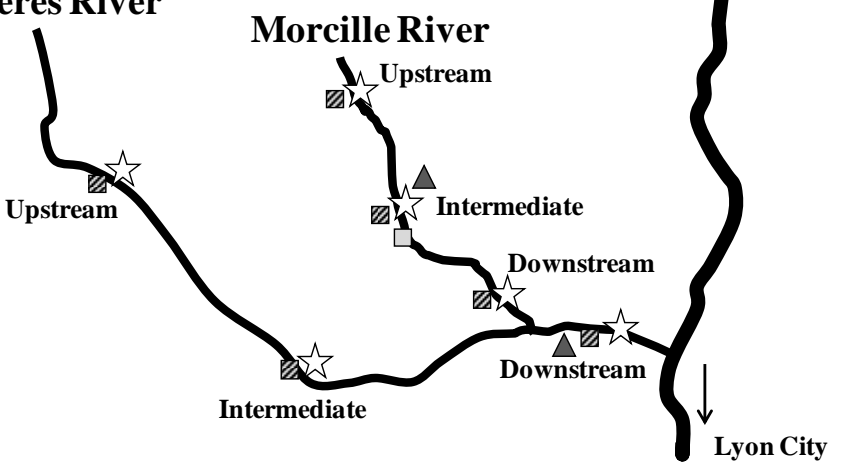

2011

Saône River
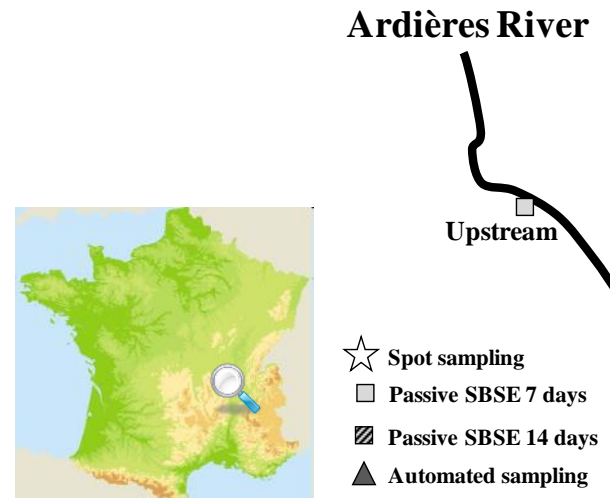

Morcille River

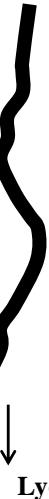

502

Figure 1. Locations of the deployment and sampling sites along the Morcille River and the Ardières River, for the spring 2010 and spring 2011 field campaigns (Beaujolais region, France). 


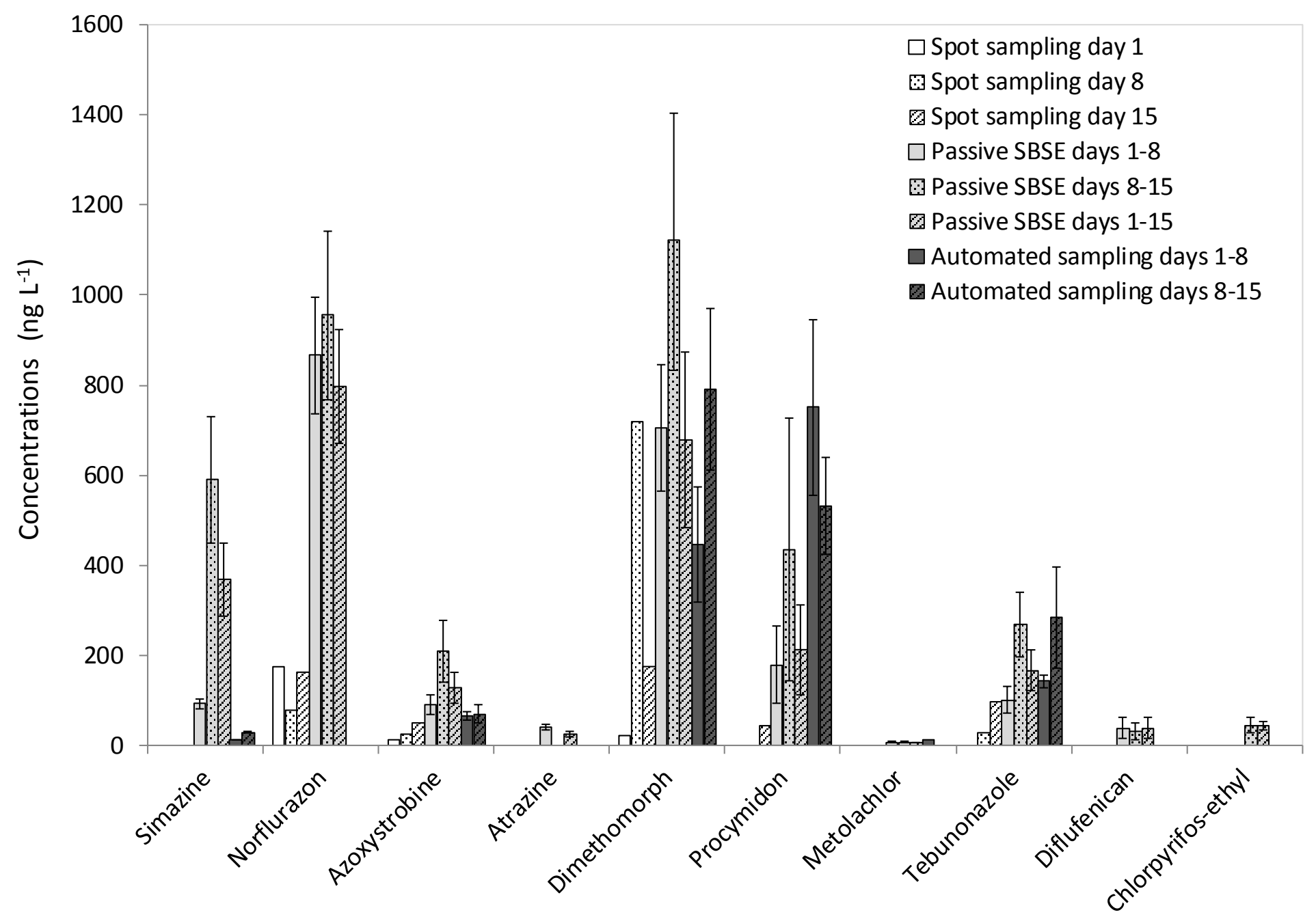

517 Figure 2. Comparison of passive SBSE $(n=3)$, spot sampling $(n=1)$ and automated sampling $(n=3)$ for the determination of the concentrations of the target pesticides at the intermediate site of the Morcille River, during the first 2 weeks of the spring 2010 field campaign. Pesticides are sorted by increasing values of $\log K_{\text {ow }}$. Error bars represent the standard deviation. Only the quantified pesticides are displayed. 
Author-produced version of the article published in Environmental Science and Pollution Research (2015), vol. 22, $n^{\circ} 6$, pp. $3997-4008$

The original publication is available at http://link.springer.com/article/10.1007\%2Fs11356-014-3590-4

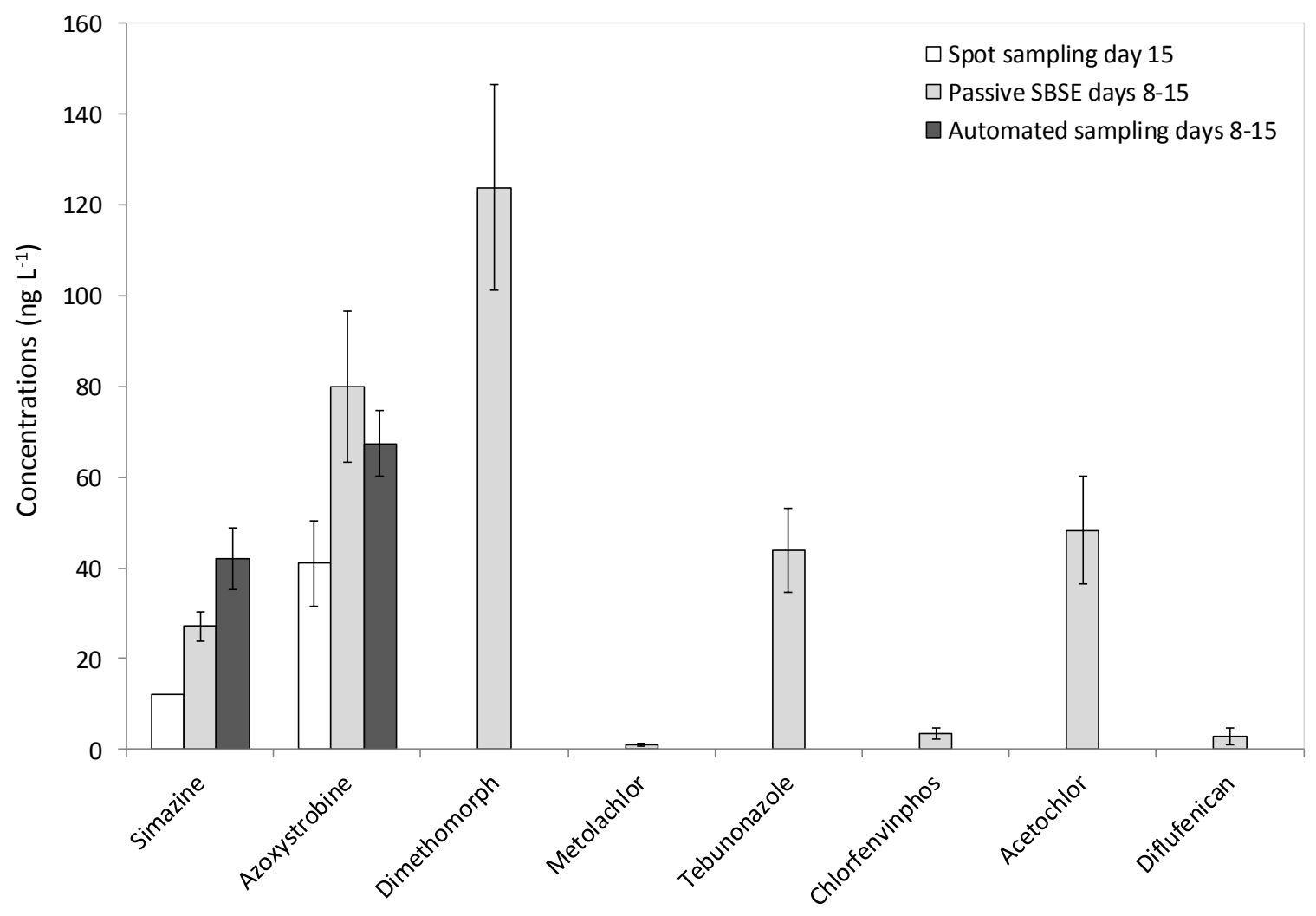

Figure 3. Comparison of passive SBSE $(n=3)$, spot sampling $(n=1)$ and automated sampling $(n=3)$ for the determination of the concentrations of the target pesticides at the downstream site of the Ardières River, during the third week of the spring 2011 field campaign. Pesticides are sorted by increasing values of $\log K_{\text {ow }}$. Error bars represent the standard deviation. Only the quantified pesticides are displayed. 
Author-produced version of the article published in Environmental Science and Pollution Research (2015), vol. 22, $n^{\circ} 6, p p .3997-4008$

The original publication is available at http://link.springer.com/article/10.1007\%2Fs11356-014-3590-4

527 Table 1. Limits of quantification of the 16 studied pesticides obtained for passive SBSE 528 followed by LD-LC-MS/MS analysis, for analytical SBSE-LD-LC-MS/MS of water samples 529 and for SPE-LC-MS/MS analysis of water samples.

\begin{tabular}{|c|c|c|c|c|c|c|}
\hline \multirow{2}{*}{ Pesticide } & \multirow{2}{*}{ Abbreviation } & \multirow{2}{*}{ Use } & \multirow{2}{*}{$\log \mathrm{K}_{\mathrm{ow}}$} & \multicolumn{3}{|c|}{ Limits of quantification $\left(\mathrm{ng} \mathrm{L}^{-1}\right)$} \\
\hline & & & & Passive SBSE & SBSE-LD-LC-MS/MS & SPE-LC-MS/MS \\
\hline Simazine & SMZ & $\mathrm{H}$ & 2.18 & 2.5 & 10 & $\mathrm{nt}$ \\
\hline Norflurazon & NFZ & $\mathrm{H}$ & 2.30 & 171 & 200 & 5.0 \\
\hline Azoxystrobine & AZS & $\mathrm{F}$ & 2.50 & 12 & 20 & 5.0 \\
\hline Atrazine & ATZ & $\mathrm{H}$ & 2.61 & 11 & 10 & nt \\
\hline Dimethomorph & DMM & $\mathrm{F}$ & 2.68 & 33 & 100 & 10 \\
\hline 3,4-dichloroaniline & DCA & M & 2.69 & 165 & 50 & 10 \\
\hline Isoproturon & IPU & $\mathrm{H}$ & 2.87 & 86 & 100 & 5.0 \\
\hline Procymidon & PCM & $\mathrm{F}$ & 3.08 & 37 & 200 & 20 \\
\hline Metolachlor & MTC & $\mathrm{H}$ & 3.13 & 0.4 & 10 & $\mathrm{nt}$ \\
\hline Fenitrothion & FNT & I & 3.32 & 6.6 & 500 & 50 \\
\hline Tebuconazole & TBZ & $\mathrm{F}$ & 3.70 & 8.1 & 100 & 5.0 \\
\hline Chlorfenvinphos & $\mathrm{CFV}$ & I & 3.81 & 2.3 & 100 & 20 \\
\hline Acetochlor & ATC & $\mathrm{H}$ & 4.14 & 32 & 100 & $\mathrm{nt}$ \\
\hline Diflufenican & DFF & $\mathrm{H}$ & 4.20 & 1.2 & 200 & 20 \\
\hline Chlorpyrifos-ethyl & $\mathrm{CPE}$ & I & 4.96 & 3.1 & 50 & 20 \\
\hline Flufenoxuron & FFX & I & 5.11 & 25 & 200 & 20 \\
\hline
\end{tabular}


Table 2. Concentrations of pesticides in the Ardières River and the Morcille River obtained from passive SBSE $(n=3)$, spot sampling $(n=1)$ and automated sampling $(\mathrm{n}=3)$ during the spring 2010 campaign. Only pesticides quantified at least once are displayed.

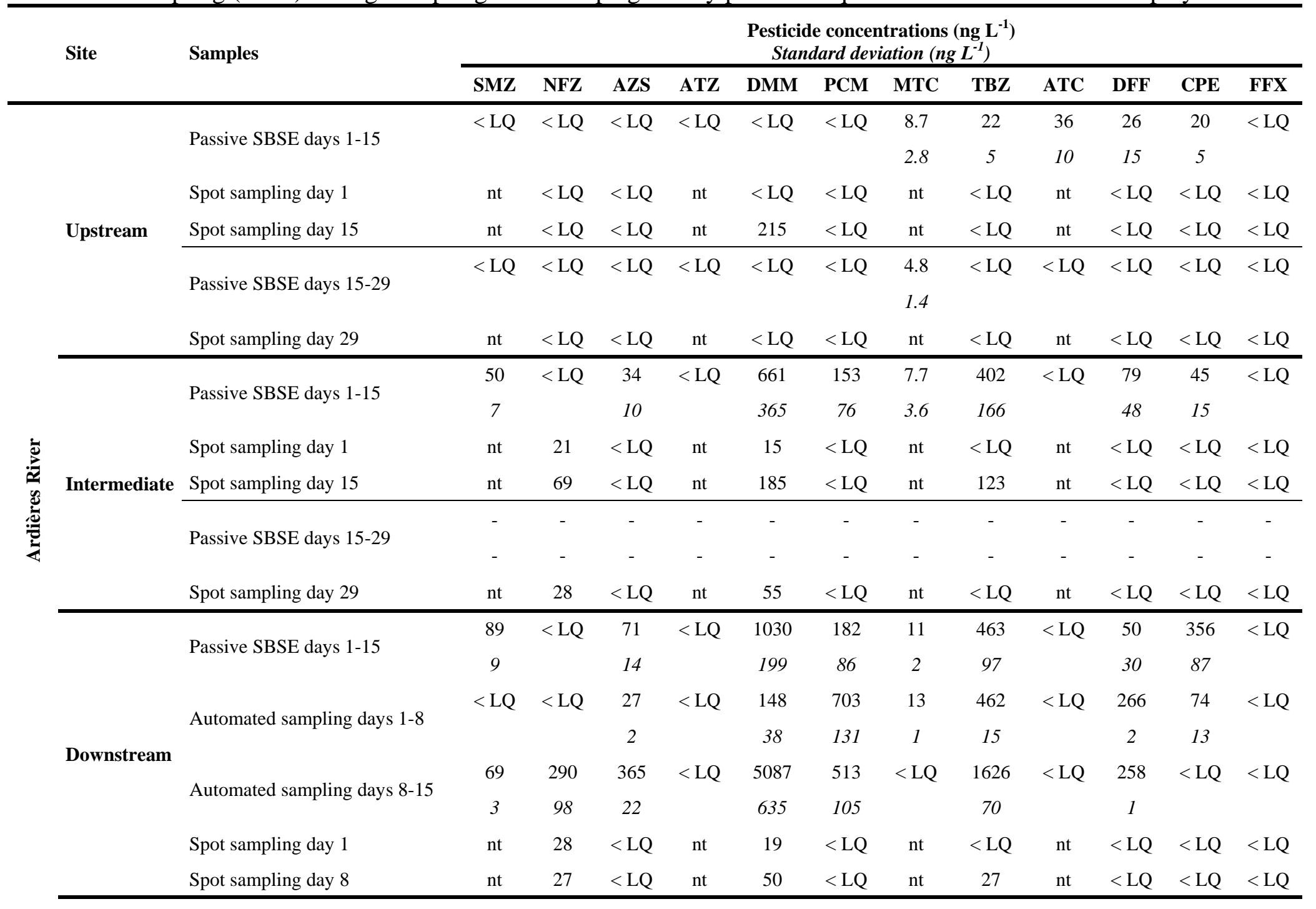




\begin{tabular}{|c|c|c|c|c|c|c|c|c|c|c|c|c|c|c|}
\hline \multirow[t]{2}{*}{ 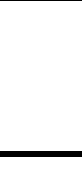 } & \multirow[t]{2}{*}{ Site } & \multirow[t]{2}{*}{ Samples } & \multicolumn{12}{|c|}{$\begin{array}{l}\text { Pesticide concentrations }\left(\mathrm{ng} \mathrm{L}^{-1}\right) \\
\text { Standard deviation }\left(\operatorname{ng} L^{-1}\right)\end{array}$} \\
\hline & & & SMZ & NFZ & AZS & ATZ & DMM & PCM & MTC & TBZ & ATC & DFF & CPE & FFX \\
\hline \multirow{9}{*}{ 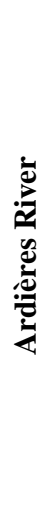 } & \multirow{9}{*}{ Downstream } & Spot sampling day 15 & $\mathrm{nt}$ & 72.1 & 18.3 & $\mathrm{nt}$ & 23.5 & $<L Q$ & $\mathrm{nt}$ & 97.0 & $\mathrm{nt}$ & $<\mathrm{LQ}$ & $<\mathrm{LQ}$ & $<\mathrm{LQ}$ \\
\hline & & \multirow{2}{*}{ Passive SBSE days 15-29 } & 42 & $<\mathrm{LQ}$ & 64 & $<\mathrm{LQ}$ & 668 & 157 & 7.1 & 303 & $<\mathrm{LQ}$ & 28 & 33 & $<\mathrm{LQ}$ \\
\hline & & & 5 & & 57 & & 243 & 75 & 2.2 & 67 & & 16 & 19 & \\
\hline & & \multirow{2}{*}{ Automated sampling days $15-22$} & 66 & $<\mathrm{LQ}$ & 11 & $<\mathrm{LQ}$ & 592 & $<\mathrm{LQ}$ & $<\mathrm{LQ}$ & 180 & $<\mathrm{LQ}$ & $<\mathrm{LQ}$ & $<\mathrm{LQ}$ & $<\mathrm{LQ}$ \\
\hline & & & 33 & & - & & 111 & & & 49 & & & & \\
\hline & & \multirow{2}{*}{ Automated sampling days 22-29 } & $<\mathrm{LQ}$ & $<\mathrm{LQ}$ & 12 & $<\mathrm{LQ}$ & 881 & $<\mathrm{LQ}$ & $<\mathrm{LQ}$ & 130 & $<\mathrm{LQ}$ & $<\mathrm{LQ}$ & $<\mathrm{LQ}$ & $<\mathrm{LQ}$ \\
\hline & & & & & 8 & & 195 & & & 76 & & & & \\
\hline & & Spot sampling day 22 & $\mathrm{nt}$ & 105 & 88 & $\mathrm{nt}$ & 2113 & 28 & $\mathrm{nt}$ & 493 & $\mathrm{nt}$ & $<\mathrm{LQ}$ & $<\mathrm{LQ}$ & $<\mathrm{LQ}$ \\
\hline & & Spot sampling day 29 & $\mathrm{nt}$ & 34 & $<\mathrm{LQ}$ & $\mathrm{nt}$ & 72 & $<\mathrm{LQ}$ & $\mathrm{nt}$ & 21 & nt & $<\mathrm{LQ}$ & $<\mathrm{LQ}$ & $<\mathrm{LQ}$ \\
\hline \multirow{13}{*}{ 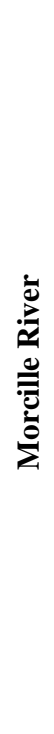 } & \multirow{7}{*}{ Upstream } & \multirow{2}{*}{ Passive SBSE days 1-15 } & 45 & $<\mathrm{LQ}$ & $<\mathrm{LQ}$ & $<\mathrm{LQ}$ & $<\mathrm{LQ}$ & $<\mathrm{LQ}$ & 4.9 & 33 & $<\mathrm{LQ}$ & $<\mathrm{LQ}$ & $<\mathrm{LQ}$ & $<\mathrm{LQ}$ \\
\hline & & & 5 & & & & & & 1.0 & 7 & & & & \\
\hline & & Spot sampling day 1 & $\mathrm{nt}$ & 12 & $<\mathrm{LQ}$ & $\mathrm{nt}$ & 11 & $<\mathrm{LQ}$ & $\mathrm{nt}$ & $<\mathrm{LQ}$ & $\mathrm{nt}$ & $<\mathrm{LQ}$ & $<\mathrm{LQ}$ & $<\mathrm{LQ}$ \\
\hline & & Spot sampling day 15 & $\mathrm{nt}$ & 19 & $<\mathrm{LQ}$ & $\mathrm{nt}$ & 11 & $<\mathrm{LQ}$ & nt & $<\mathrm{LQ}$ & nt & $<\mathrm{LQ}$ & $<\mathrm{LQ}$ & $<\mathrm{LQ}$ \\
\hline & & \multirow{2}{*}{ Passive SBSE days 15-29 } & $<\mathrm{LQ}$ & $<\mathrm{LQ}$ & $<\mathrm{LQ}$ & $<\mathrm{LQ}$ & $<\mathrm{LQ}$ & 126 & $<\mathrm{LQ}$ & $<\mathrm{LQ}$ & $<\mathrm{LQ}$ & $<\mathrm{LQ}$ & $<\mathrm{LQ}$ & $<\mathrm{LQ}$ \\
\hline & & & & & & & & 59 & & & & & & \\
\hline & & Spot sampling day 29 & $\mathrm{nt}$ & 17 & $<\mathrm{LQ}$ & $\mathrm{nt}$ & $<\mathrm{LQ}$ & $<\mathrm{LQ}$ & nt & $<\mathrm{LQ}$ & nt & $<\mathrm{LQ}$ & $<\mathrm{LQ}$ & $<\mathrm{LQ}$ \\
\hline & \multirow{6}{*}{ Intermediate } & \multirow{2}{*}{ Passive SBSE days 1-8 } & 92 & 867 & 91 & 40 & 706 & 178 & 7.4 & 101 & $<\mathrm{LQ}$ & 39 & $<\mathrm{LQ}$ & $<\mathrm{LQ}$ \\
\hline & & & 12 & 129 & 21 & 7 & 140 & 86 & 1.6 & 29 & & 23 & & \\
\hline & & \multirow{2}{*}{ Passive SBSE days 8-15 } & 589 & 956 & 210 & $<\mathrm{LQ}$ & 1120 & 435 & 6.8 & 268 & $<\mathrm{LQ}$ & 31 & 44 & $<\mathrm{LQ}$ \\
\hline & & & 140 & 187 & 69 & & 286 & 292 & 1.4 & 73 & & 18 & 18 & \\
\hline & & \multirow{2}{*}{ Passive SBSE days 1-15 } & 369 & 796 & 128 & 25 & 678 & 212 & 5.5 & 167 & $<\mathrm{LQ}$ & 39 & 43 & $<\mathrm{LQ}$ \\
\hline & & & 81 & 127 & 35 & 6 & 196 & 99 & 1.2 & 45 & & 24 & 10 & \\
\hline
\end{tabular}




\begin{tabular}{|c|c|c|c|c|c|c|c|c|c|c|c|c|c|c|}
\hline & \multirow[t]{2}{*}{ Site } & \multirow[t]{2}{*}{ Samples } & \multicolumn{12}{|c|}{$\begin{array}{c}\text { Pesticide concentrations }\left(\mathrm{ng} \mathrm{L}^{-1}\right) \\
\text { Standard deviation }\left(n g L^{-1}\right) \\
\end{array}$} \\
\hline & & & SMZ & NFZ & AZS & ATZ & DMM & PCM & MTC & TBZ & ATC & DFF & CPE & FFX \\
\hline \multirow{22}{*}{ 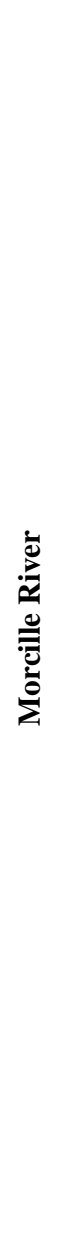 } & \multirow{19}{*}{ Intermediate } & \multirow{2}{*}{ Automated sampling days 1-8 } & 13 & $<\mathrm{LQ}$ & 66 & $<\mathrm{LQ}$ & 446 & 751 & 12 & 142 & $<\mathrm{LQ}$ & $<\mathrm{LQ}$ & $<\mathrm{LQ}$ & $<\mathrm{LQ}$ \\
\hline & & & 1 & & 10 & & 128 & 196 & - & 15 & & & & \\
\hline & & \multirow{2}{*}{ Automated sampling days 8-15 } & 28 & $<\mathrm{LQ}$ & 70 & $<\mathrm{LQ}$ & 792 & 531 & $<\mathrm{LQ}$ & 285 & $<\mathrm{LQ}$ & $<\mathrm{LQ}$ & $<\mathrm{LQ}$ & $<\mathrm{LQ}$ \\
\hline & & & 2 & & 21 & & 180 & 108 & & 112 & & & & \\
\hline & & Spot sampling day 1 & $\mathrm{nt}$ & 173 & 11 & $\mathrm{nt}$ & 23 & $<\mathrm{LQ}$ & $\mathrm{nt}$ & $<\mathrm{LQ}$ & $\mathrm{nt}$ & $<\mathrm{LQ}$ & $<\mathrm{LQ}$ & $<\mathrm{LQ}$ \\
\hline & & Spot sampling day 8 & $\mathrm{nt}$ & 78 & 27 & $\mathrm{nt}$ & 718 & $<\mathrm{LQ}$ & $\mathrm{nt}$ & 30 & $\mathrm{nt}$ & $<\mathrm{LQ}$ & $<\mathrm{LQ}$ & $<\mathrm{LQ}$ \\
\hline & & Spot sampling day 15 & $\mathrm{nt}$ & 163 & 49 & $\mathrm{nt}$ & 176 & 44 & $\mathrm{nt}$ & 96 & $\mathrm{nt}$ & $<\mathrm{LQ}$ & $<\mathrm{LQ}$ & $<\mathrm{LQ}$ \\
\hline & & \multirow{2}{*}{ Passive SBSE days $15-22$} & 213 & $<\mathrm{LQ}$ & 93 & $<\mathrm{LQ}$ & 360 & 257 & 4.2 & 225 & $<\mathrm{LQ}$ & $<\mathrm{LQ}$ & $<\mathrm{LQ}$ & $<\mathrm{LQ}$ \\
\hline & & & 31 & & 37 & & 66 & 132 & 0.8 & 75 & & & & \\
\hline & & \multirow{2}{*}{ Passive SBSE days 22-29 } & 132 & 869 & 85 & $<\mathrm{LQ}$ & 349 & 328 & 4.5 & 230 & $<\mathrm{LQ}$ & $<\mathrm{LQ}$ & $<\mathrm{LQ}$ & $<\mathrm{LQ}$ \\
\hline & & & 43 & 130 & 51 & & 64 & 194 & 1.0 & 107 & & & & \\
\hline & & \multirow{2}{*}{ Passive SBSE days 15-29 } & 198 & $<\mathrm{LQ}$ & 91 & $<\mathrm{LQ}$ & $<\mathrm{LQ}$ & 323 & 3.8 & 250 & $<\mathrm{LQ}$ & $<\mathrm{LQ}$ & $<\mathrm{LQ}$ & $<\mathrm{LQ}$ \\
\hline & & & 22 & & 20 & & & 155 & 0.7 & 73 & & & & \\
\hline & & \multirow{2}{*}{ Automated sampling days $15-22$} & 408 & 329 & 73 & $<\mathrm{LQ}$ & 459 & $<\mathrm{LQ}$ & $<\mathrm{LQ}$ & 116 & $<\mathrm{LQ}$ & $<\mathrm{LQ}$ & $<\mathrm{LQ}$ & $<\mathrm{LQ}$ \\
\hline & & & 72 & 59 & 6 & & 43 & & & 8 & & & & \\
\hline & & \multirow{2}{*}{ Automated sampling days $22-29$} & 106 & 487 & 72 & $<\mathrm{LQ}$ & 331 & $<\mathrm{LQ}$ & $<\mathrm{LQ}$ & 126 & $<\mathrm{LQ}$ & $<\mathrm{LQ}$ & $<\mathrm{LQ}$ & $<\mathrm{LQ}$ \\
\hline & & & 20 & 238 & 10 & & 26 & & & 13 & & & & \\
\hline & & Spot sampling day 22 & $\mathrm{nt}$ & 129 & 84 & $\mathrm{nt}$ & 167 & 24 & $\mathrm{nt}$ & 129 & $\mathrm{nt}$ & $<\mathrm{LQ}$ & $<\mathrm{LQ}$ & $<\mathrm{LQ}$ \\
\hline & & Spot sampling day 29 & $\mathrm{nt}$ & 105 & 29 & $\mathrm{nt}$ & 56 & 26 & $\mathrm{nt}$ & 38 & $\mathrm{nt}$ & $<\mathrm{LQ}$ & $<\mathrm{LQ}$ & $<\mathrm{LQ}$ \\
\hline & \multirow{3}{*}{ Downstream } & \multirow{2}{*}{ Passive SBSE days 1-15 } & 293 & 862 & 200 & $<\mathrm{LQ}$ & 1248 & 222 & 5.8 & 469 & $<\mathrm{LQ}$ & 35 & 9011 & $<\mathrm{LQ}$ \\
\hline & & & 86 & 176 & 86 & & 651 & 116 & 1.1 & 243 & & 21 & 2227 & \\
\hline & & Spot sampling day 1 & $\mathrm{nt}$ & 52 & 17 & $\mathrm{nt}$ & 36 & $<\mathrm{LQ}$ & nt & 20 & nt & $<\mathrm{LQ}$ & $<\mathrm{LQ}$ & $<\mathrm{LQ}$ \\
\hline
\end{tabular}




\begin{tabular}{|c|c|c|c|c|c|c|c|c|c|c|c|c|c|}
\hline \multirow[t]{2}{*}{ Site } & \multirow[t]{2}{*}{ Samples } & \multicolumn{12}{|c|}{$\begin{array}{l}\text { Pesticide concentrations }\left(\mathrm{ng} \mathrm{L}^{-1}\right) \\
\text { Standard deviation }\left(n g L^{-1}\right)\end{array}$} \\
\hline & & SMZ & NFZ & AZS & ATZ & DMM & PCM & MTC & TBZ & ATC & DFF & CPE & FFX \\
\hline \multirow{4}{*}{ Downstream } & Spot sampling day 15 & $\mathrm{nt}$ & 148 & 75 & $\mathrm{nt}$ & 242 & 35 & $\mathrm{nt}$ & 102 & $\mathrm{nt}$ & $<\mathrm{LQ}$ & $<\mathrm{LQ}$ & $<\mathrm{LQ}$ \\
\hline & \multirow{2}{*}{ Passive SBSE days 15-29 } & 103 & $<\mathrm{LQ}$ & 72 & $<\mathrm{LQ}$ & 969 & 240 & 5.1 & 418 & $<\mathrm{LQ}$ & 33 & 783 & 596 \\
\hline & & 31 & & 23 & & 429 & 159 & 1.4 & 198 & & 20 & 471 & 448 \\
\hline & Spot sampling day 29 & $\mathrm{nt}$ & 116 & 29 & $\mathrm{nt}$ & 137 & 27 & $\mathrm{nt}$ & 57 & $\mathrm{nt}$ & $<\mathrm{LQ}$ & $<\mathrm{LQ}$ & $<\mathrm{LQ}$ \\
\hline
\end{tabular}

LQ: limit of quantification; nt: non tageted 
Table 3. Concentrations of pesticides in the Ardières River and the Morcille River obtained from passive SBSE $(n=3)$, spot sampling $(n=3)$ and automated sampling $(\mathrm{n}=3)$ during the spring 2011 campaign. Only pesticides quantified at least once are displayed.

\begin{tabular}{|c|c|c|c|c|c|c|c|c|c|c|c|c|c|c|c|}
\hline \multirow[t]{2}{*}{. } & \multirow[t]{2}{*}{ Site } & \multirow[t]{2}{*}{ Samples } & \multicolumn{13}{|c|}{$\begin{array}{l}\text { Pesticide concentrations }\left(\mathrm{ng} \mathrm{L}^{-1}\right) \\
\text { Standard deviation }\left(n g L^{-1}\right)\end{array}$} \\
\hline & & & SMZ & NFZ & AZS & ATZ & DMM & DCA & PCM & MTC & TBZ & $\mathrm{CFV}$ & ATC & DFF & CPE \\
\hline \multirow{23}{*}{ 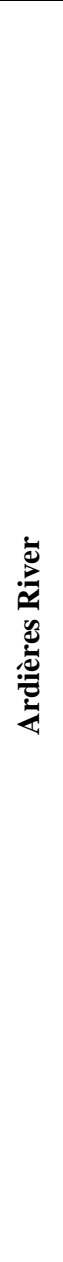 } & \multirow{8}{*}{ Upstream } & \multirow{2}{*}{ Passive SBSE days 1-8 } & $<\mathrm{LQ}$ & $<\mathrm{LQ}$ & $<\mathrm{LQ}$ & $<\mathrm{LQ}$ & $<\mathrm{LQ}$ & $<\mathrm{LQ}$ & $<\mathrm{LQ}$ & $<\mathrm{LQ}$ & $<\mathrm{LQ}$ & $<\mathrm{LQ}$ & $<\mathrm{LQ}$ & 2.6 & $<\mathrm{LQ}$ \\
\hline & & & & & & & & & & & & & & 1.5 & \\
\hline & & \multirow{2}{*}{ Passive SBSE days 8-15 } & $<\mathrm{LQ}$ & $<\mathrm{LQ}$ & $<\mathrm{LQ}$ & $<\mathrm{LQ}$ & $<\mathrm{LQ}$ & $<\mathrm{LQ}$ & $<\mathrm{LQ}$ & $<\mathrm{LQ}$ & $<\mathrm{LQ}$ & $<\mathrm{LQ}$ & 816 & 2.3 & $<\mathrm{LQ}$ \\
\hline & & & & & & & & & & & & & 196 & 1.4 & \\
\hline & & \multirow{2}{*}{ Passive SBSE days $15-22$} & $<\mathrm{LQ}$ & $<\mathrm{LQ}$ & $<\mathrm{LQ}$ & 8.6 & $<\mathrm{LQ}$ & $<\mathrm{LQ}$ & $<\mathrm{LQ}$ & 0.4 & $<\mathrm{LQ}$ & $<\mathrm{LQ}$ & 429 & 1.7 & 12 \\
\hline & & & & & & 2.2 & & & & 0.2 & & & 115 & 1.1 & 3 \\
\hline & & \multirow{2}{*}{ Passive SBSE days 22-29 } & $<\mathrm{LQ}$ & $<\mathrm{LQ}$ & $<\mathrm{LQ}$ & 9.0 & $<\mathrm{LQ}$ & $<\mathrm{LQ}$ & $<\mathrm{LQ}$ & $<\mathrm{LQ}$ & $<\mathrm{LQ}$ & 4.1 & 216 & 3.1 & $<\mathrm{LQ}$ \\
\hline & & & & & & 2.4 & & & & & & 1.8 & 64 & 3.0 & \\
\hline & \multirow{15}{*}{ Downstream } & \multirow{2}{*}{ Passive SBSE days $1-8$} & 10 & $<\mathrm{LQ}$ & 70 & $<\mathrm{LQ}$ & $<\mathrm{LQ}$ & $<\mathrm{LQ}$ & $<\mathrm{LQ}$ & $<\mathrm{LQ}$ & 21 & $<\mathrm{LQ}$ & $<\mathrm{LQ}$ & 2.3 & $<\mathrm{LQ}$ \\
\hline & & & 3 & & 22 & & & & & & 8 & & & 1.4 & \\
\hline & & Spot sampling day 8 & $<\mathrm{LQ}$ & $<\mathrm{LQ}$ & $<\mathrm{LQ}$ & $<\mathrm{LQ}$ & $<\mathrm{LQ}$ & $<\mathrm{LQ}$ & $<\mathrm{LQ}$ & $<\mathrm{LQ}$ & $<\mathrm{LQ}$ & $<\mathrm{LQ}$ & $<\mathrm{LQ}$ & $<\mathrm{LQ}$ & $<\mathrm{LQ}$ \\
\hline & & \multirow{2}{*}{ Automated sampling days 1-8 } & $<\mathrm{LQ}$ & $<\mathrm{LQ}$ & 61 & $<\mathrm{LQ}$ & $<\mathrm{LQ}$ & $<\mathrm{LQ}$ & $<\mathrm{LQ}$ & $<\mathrm{LQ}$ & $<\mathrm{LQ}$ & $<\mathrm{LQ}$ & $<\mathrm{LQ}$ & $<\mathrm{LQ}$ & $<\mathrm{LQ}$ \\
\hline & & & & & 6 & & & & & & & & & & \\
\hline & & \multirow{2}{*}{ Passive SBSE days 8-15 } & 61 & $<\mathrm{LQ}$ & 18 & $<\mathrm{LQ}$ & 93 & $<\mathrm{LQ}$ & $<\mathrm{LQ}$ & $<\mathrm{LQ}$ & 58 & $<\mathrm{LQ}$ & $<\mathrm{LQ}$ & 10 & $<\mathrm{LQ}$ \\
\hline & & & 10 & & 4 & & 42 & & & & 14 & & & 12 & \\
\hline & & \multirow{2}{*}{ Automated sampling days 8-15 } & 108 & $<\mathrm{LQ}$ & 25 & $<\mathrm{LQ}$ & $<\mathrm{LQ}$ & 61 & $<\mathrm{LQ}$ & $<\mathrm{LQ}$ & $<\mathrm{LQ}$ & $<\mathrm{LQ}$ & 104 & $<\mathrm{LQ}$ & $<\mathrm{LQ}$ \\
\hline & & & 3 & & 2 & & & - & & & & & 2 & & \\
\hline & & \multirow{2}{*}{ Passive SBSE days 15-22 } & 27 & $<\mathrm{LQ}$ & 80 & $<\mathrm{LQ}$ & 124 & $<\mathrm{LQ}$ & $<\mathrm{LQ}$ & 1.1 & 44 & 3.4 & 48 & 2.9 & $<\mathrm{LQ}$ \\
\hline & & & 3 & & 17 & & 23 & & & 0.3 & 9 & 1.2 & 12 & 1.8 & \\
\hline & & \multirow{2}{*}{ Spot sampling day 22} & 12 & $<\mathrm{LQ}$ & 41 & $<\mathrm{LQ}$ & $<\mathrm{LQ}$ & $<\mathrm{LQ}$ & $<\mathrm{LQ}$ & $<\mathrm{LQ}$ & $<\mathrm{LQ}$ & $<\mathrm{LQ}$ & $<\mathrm{LQ}$ & $<\mathrm{LQ}$ & $<\mathrm{LQ}$ \\
\hline & & & - & & 10 & & & & & & & & & & \\
\hline & & \multirow{2}{*}{ Automated sampling days $15-22$} & 42 & $<\mathrm{LQ}$ & 67 & $<\mathrm{LQ}$ & $<\mathrm{LQ}$ & $<\mathrm{LQ}$ & $<\mathrm{LQ}$ & $<\mathrm{LQ}$ & $<\mathrm{LQ}$ & $<\mathrm{LQ}$ & $<\mathrm{LQ}$ & $<\mathrm{LQ}$ & $<\mathrm{LQ}$ \\
\hline & & & 7 & & 7 & & & & & & & & & & \\
\hline
\end{tabular}




\begin{tabular}{|c|c|c|c|c|c|c|c|c|c|c|c|c|c|c|c|}
\hline & \multirow[t]{2}{*}{ Site } & \multirow[t]{2}{*}{ Samples } & \multicolumn{13}{|c|}{$\begin{array}{l}\text { Pesticide concentrations }\left(\mathrm{ng} \mathrm{L}^{-1}\right) \\
\text { Standard deviation }\left(n g L^{-1}\right)\end{array}$} \\
\hline & & & SMZ & NFZ & AZS & ATZ & DMM & DCA & PCM & MTC & TBZ & CFV & ATC & DFF & CPE \\
\hline \multirow{6}{*}{ 营 } & \multirow{6}{*}{ Downstream } & \multirow{2}{*}{ Passive SBSE days 22-29 } & 111 & $<\mathrm{LQ}$ & 79 & 7.9 & 494 & $<\mathrm{LQ}$ & $<\mathrm{LQ}$ & 2.6 & 169 & 3.4 & $<\mathrm{LQ}$ & 11 & $<\mathrm{LQ}$ \\
\hline & & & 29 & & 30 & 1.4 & 91 & & & 0.6 & 51 & 1.2 & & 8 & \\
\hline & & \multirow{2}{*}{ Spot sampling day 29} & 31 & $<\mathrm{LQ}$ & 22 & $<\mathrm{LQ}$ & $<\mathrm{LQ}$ & $<\mathrm{LQ}$ & $<\mathrm{LQ}$ & $<\mathrm{LQ}$ & $<\mathrm{LQ}$ & $<\mathrm{LQ}$ & $<\mathrm{LQ}$ & $<\mathrm{LQ}$ & $<\mathrm{LQ}$ \\
\hline & & & 6 & & - & & & & & & & & & & \\
\hline & & \multirow{2}{*}{ Automated sampling days 22-29 } & 31 & 294 & 38 & $<\mathrm{LQ}$ & 317 & $<\mathrm{LQ}$ & $<\mathrm{LQ}$ & $<\mathrm{LQ}$ & 111 & $<\mathrm{LQ}$ & $<\mathrm{LQ}$ & $<\mathrm{LQ}$ & $<\mathrm{LQ}$ \\
\hline & & & 5 & 115 & 2 & & 29 & & & & 3 & & & & \\
\hline \multirow{13}{*}{ 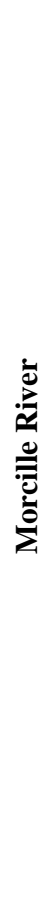 } & \multirow{13}{*}{ Intermediate } & \multirow{2}{*}{ Passive SBSE days 1-8 } & 10 & $<\mathrm{LQ}$ & $<\mathrm{LQ}$ & $<\mathrm{LQ}$ & 71 & $<\mathrm{LQ}$ & $<\mathrm{LQ}$ & $<\mathrm{LQ}$ & 20 & $<\mathrm{LQ}$ & $<\mathrm{LQ}$ & $<\mathrm{LQ}$ & $<\mathrm{LQ}$ \\
\hline & & & 1 & & & & 13 & & & & 5 & & & & \\
\hline & & Spot sampling day 8 & $<\mathrm{LQ}$ & $<\mathrm{LQ}$ & $<\mathrm{LQ}$ & $<\mathrm{LQ}$ & $<\mathrm{LQ}$ & $<\mathrm{LQ}$ & $<\mathrm{LQ}$ & $<\mathrm{LQ}$ & $<\mathrm{LQ}$ & $<\mathrm{LQ}$ & $<\mathrm{LQ}$ & $<\mathrm{LQ}$ & $<\mathrm{LQ}$ \\
\hline & & Automated sampling days 1-8 & $<\mathrm{LQ}$ & $<\mathrm{LQ}$ & $<\mathrm{LQ}$ & $<\mathrm{LQ}$ & $<\mathrm{LQ}$ & $<\mathrm{LQ}$ & $<\mathrm{LQ}$ & $<\mathrm{LQ}$ & $<\mathrm{LQ}$ & $<\mathrm{LQ}$ & $<\mathrm{LQ}$ & $<\mathrm{LQ}$ & $<\mathrm{LQ}$ \\
\hline & & \multirow{2}{*}{ Passive SBSE days 8-15 } & 11 & $<\mathrm{LQ}$ & $<\mathrm{LQ}$ & $<\mathrm{LQ}$ & 393 & $<\mathrm{LQ}$ & $<\mathrm{LQ}$ & $<\mathrm{LQ}$ & 44 & $<\mathrm{LQ}$ & $<\mathrm{LQ}$ & $<\mathrm{LQ}$ & $<\mathrm{LQ}$ \\
\hline & & & 4 & & & & 149 & & & & 21 & & & & \\
\hline & & \multirow{2}{*}{ Automated sampling days 8-15 } & $<\mathrm{LQ}$ & $<\mathrm{LQ}$ & $<\mathrm{LQ}$ & $<\mathrm{LQ}$ & 477 & $<\mathrm{LQ}$ & $<\mathrm{LQ}$ & $<\mathrm{LQ}$ & $<\mathrm{LQ}$ & $<\mathrm{LQ}$ & $<\mathrm{LQ}$ & $<\mathrm{LQ}$ & $<\mathrm{LQ}$ \\
\hline & & & & & & & 43 & & & & & & & & \\
\hline & & \multirow{2}{*}{ Passive SBSE days 15-22 } & 13 & $<\mathrm{LQ}$ & $<\mathrm{LQ}$ & $<\mathrm{LQ}$ & 181 & $<\mathrm{LQ}$ & $<\mathrm{LQ}$ & 0.5 & 60 & 4.2 & $<\mathrm{LQ}$ & 1.1 & 3.5 \\
\hline & & & 1 & & & & 33 & & & 0.2 & 13 & 1.6 & & 0.7 & 0.8 \\
\hline & & Spot sampling day 22 & $<\mathrm{LQ}$ & $<\mathrm{LQ}$ & $<\mathrm{LQ}$ & $<\mathrm{LQ}$ & $<\mathrm{LQ}$ & $<\mathrm{LQ}$ & $<\mathrm{LQ}$ & $<\mathrm{LQ}$ & $<\mathrm{LQ}$ & $<\mathrm{LQ}$ & $<\mathrm{LQ}$ & $<\mathrm{LQ}$ & $<\mathrm{LQ}$ \\
\hline & & \multirow{2}{*}{ Automated sampling days $15-22$} & $<\mathrm{LQ}$ & $<\mathrm{LQ}$ & $<\mathrm{LQ}$ & $<\mathrm{LQ}$ & 111 & $<\mathrm{LQ}$ & $<\mathrm{LQ}$ & $<\mathrm{LQ}$ & $<\mathrm{LQ}$ & $<\mathrm{LQ}$ & $<\mathrm{LQ}$ & $<\mathrm{LQ}$ & $<\mathrm{LQ}$ \\
\hline & & & & & & & 2 & & & & & & & & \\
\hline
\end{tabular}




\begin{tabular}{|c|c|c|c|c|c|c|c|c|c|c|c|c|c|c|}
\hline \multirow[t]{2}{*}{ Site } & \multirow[t]{2}{*}{ Samples } & \multicolumn{13}{|c|}{ 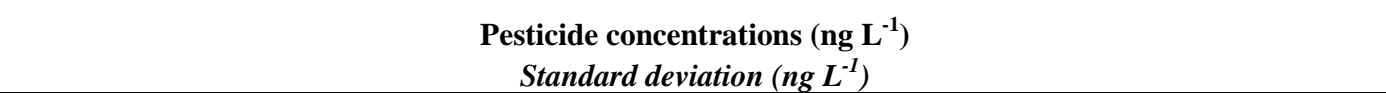 } \\
\hline & & SMZ & NFZ & AZS & ATZ & DMM & DCA & PCM & MTC & TBZ & CFV & ATC & DFF & CPE \\
\hline & \multirow{2}{*}{ Passive SBSE days 22-29 } & 26 & $<\mathrm{LQ}$ & 43 & $<\mathrm{LQ}$ & $<\mathrm{LQ}$ & $<\mathrm{LQ}$ & 48 & 0.9 & 249 & $<\mathrm{LQ}$ & $<\mathrm{LQ}$ & 2.5 & $<\mathrm{LQ}$ \\
\hline & & 2 & & 12 & & & & 23 & 0.3 & 59 & & & 1.6 & \\
\hline & Spot sampling day 29 & $<\mathrm{LQ}$ & $<\mathrm{LQ}$ & $<\mathrm{LQ}$ & $<\mathrm{LQ}$ & $<\mathrm{LQ}$ & $<\mathrm{LQ}$ & $<\mathrm{LQ}$ & $<\mathrm{LQ}$ & $<\mathrm{LQ}$ & $<\mathrm{LQ}$ & $<\mathrm{LQ}$ & $<\mathrm{LQ}$ & $<\mathrm{LQ}$ \\
\hline & \multirow{2}{*}{ Automated sampling days 22-29 } & 13 & $<\mathrm{LQ}$ & 22 & $<\mathrm{LQ}$ & 169 & $<\mathrm{LQ}$ & $<\mathrm{LQ}$ & $<\mathrm{LQ}$ & 197 & $<\mathrm{LQ}$ & $<\mathrm{LQ}$ & $<\mathrm{LQ}$ & $<\mathrm{LQ}$ \\
\hline & & - & & - & & 88 & & & & 26 & & & & \\
\hline \multirow{4}{*}{ Downstream } & \multirow{2}{*}{ Passive SBSE days 1-8 } & 16 & $<\mathrm{LQ}$ & 77 & $<\mathrm{LQ}$ & 99 & $<\mathrm{LQ}$ & $<\mathrm{LQ}$ & $<\mathrm{LQ}$ & 113 & $<\mathrm{LQ}$ & $<\mathrm{LQ}$ & 2.5 & $<\mathrm{LQ}$ \\
\hline & & 2 & & 23 & & 19 & & & & 38 & & & 2.1 & \\
\hline & \multirow{2}{*}{ Passive SBSE days 8-15 } & 12 & $<\mathrm{LQ}$ & 24 & $<\mathrm{LQ}$ & 82 & $<\mathrm{LQ}$ & $<\mathrm{LQ}$ & $<\mathrm{LQ}$ & 112 & $<\mathrm{LQ}$ & $<\mathrm{LQ}$ & 12 & $<\mathrm{LQ}$ \\
\hline & & 3 & & 20 & & 60 & & & & 41 & & & 7 & \\
\hline
\end{tabular}


Author-produced version of the article published in Environmental Science and Pollution Research (2015), vol. 22, $n^{\circ} 6$, pp. $3997-4008$

The original publication is available at http://link.springer.com/article/10.1007\%2Fs $11356-014-3590-4$

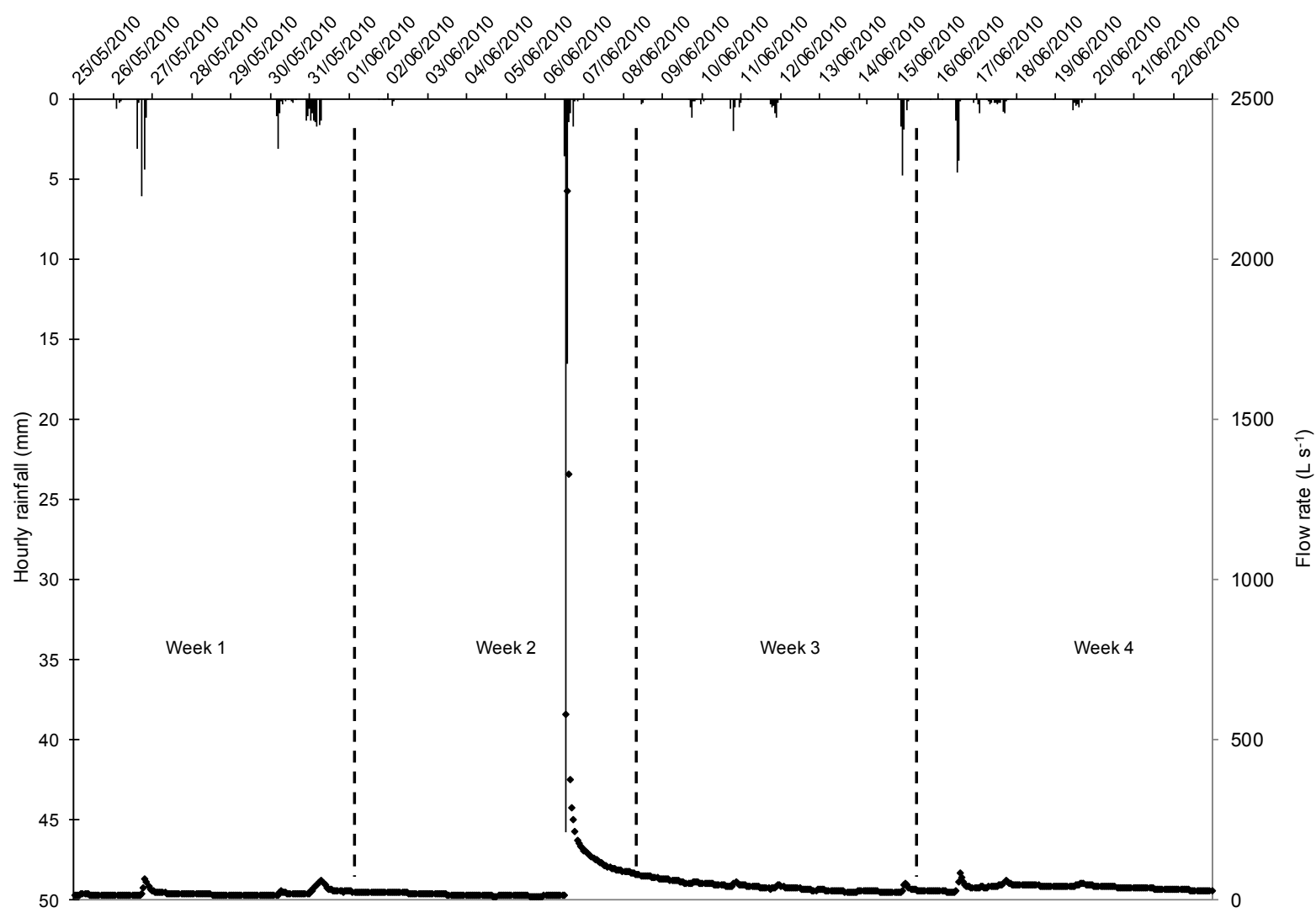

Figure S1. Hourly rainfall (in $\mathrm{mm}$ ) and flow rate at the intermediate site of the Morcille River (in $\mathrm{L} \mathrm{s}^{-1}$ ) during the spring 2010 campaign. 
Author-produced version of the article published in Environmental Science and Pollution Research (2015), vol. 22, $n^{\circ} 6, p p .3997-4008$

The original publication is available at http://link.springer.com/article/10.1007\%2Fs11356-014-3590-4 doi:10.1007/s11356-014-3590-4

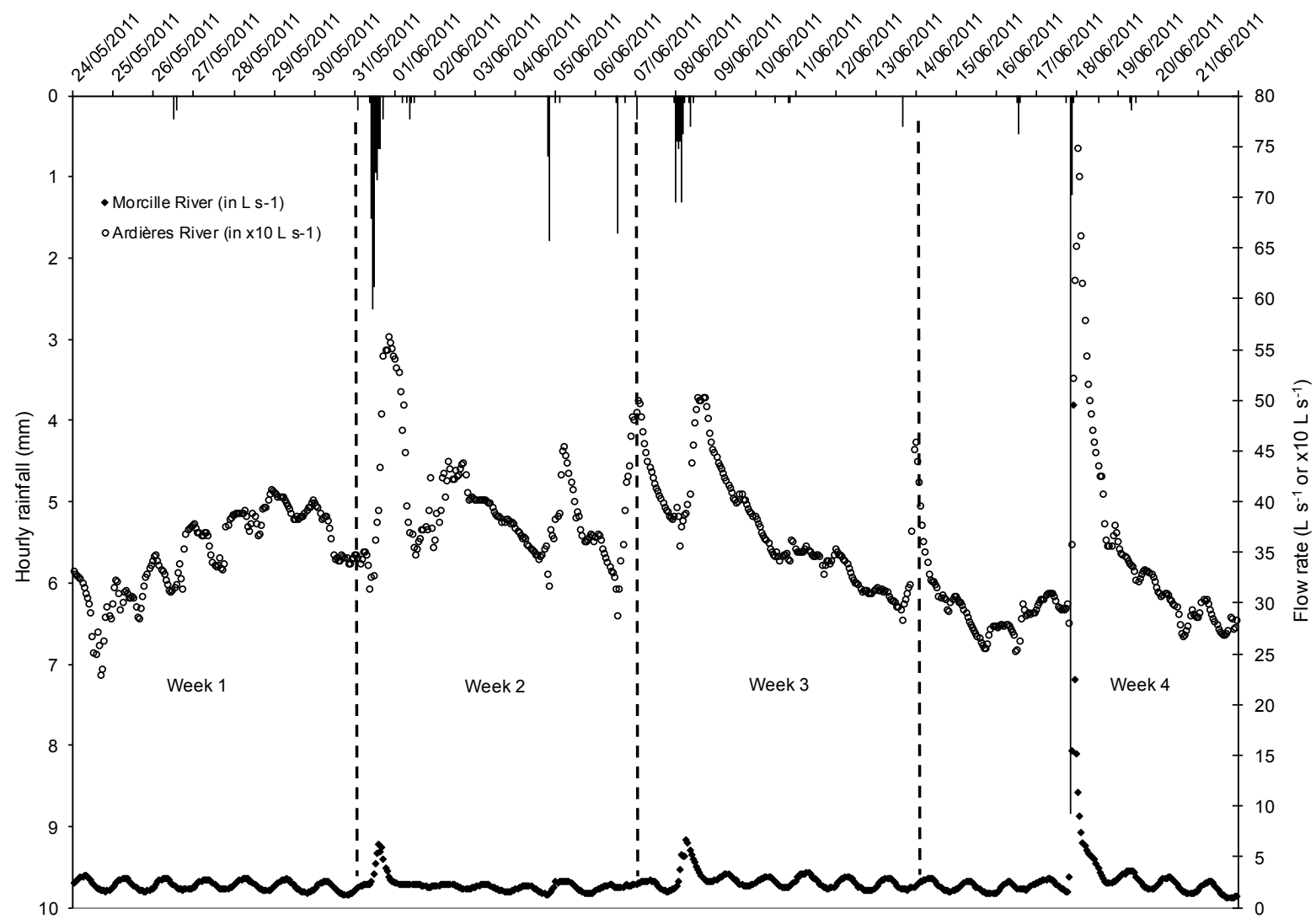

Figure S2. Hourly rainfall (in $\mathrm{mm}$ ) and flow rate at the intermediate site of the Morcille River (in $\mathrm{L} \mathrm{s}^{-1}$ ) and at the downstream site of the Ardières River (in $\times 10 \mathrm{~L} \mathrm{~s}^{-1}$ ) during the spring 2011 campaign. 